\title{
Resistance to Benzimidazole and Dicarboximide Fungicides in Greenhouse Isolates of Botrytis cinerea
}

\author{
L. F. Yourman and S. N. Jeffers, Department of Plant Pathology and Physiology, Clemson University, Clemson SC \\ 29634-0377
}

\begin{abstract}
Yourman, L. F., and Jeffers, S. N. 1999. Resistance to benzimidazole and dicarboximide fungicides in greenhouse isolates of Botrytis cinerea. Plant Dis. 83:569-575.
\end{abstract}

In 1996 and 1997, 325 isolates of Botrytis cinerea were collected from 35 commercial greenhouses growing ornamental crops in South Carolina to determine the incidence of resistance to benzimidazole and dicarboximide fungicides. Conidium germination was assessed on a defined agar medium amended with either thiophanate-methyl (a benzimidazole) or vinclozolin (a dicarboximide). A total of 53 representative isolates were evaluated further for conidium germination and mycelium growth on fungicide-amended medium and for infection of geranium seedlings treated with thiophanate-methyl or vinclozolin at label rates. Isolates were considered sensitive to thiophanate-methyl or vinclozolin when the effective concentration of the fungicide active ingredient resulting in 50\% inhibition of germination $\left(\mathrm{EC}_{50}\right.$-germ) was $\leq 5 \mu \mathrm{g} / \mathrm{ml}$ or when the effective concentration of fungicide active ingredient resulting in 50\% inhibition of mycelium growth $\left(\mathrm{EC}_{50}\right.$-growth) was $\leq 1 \mu \mathrm{g} / \mathrm{ml}$. Of all isolates, $81 \%(262 / 325)$ were resistant to thiophanate-methyl and 69\% (223/325) were resistant to vinclozolin. Four phenotypes were observed: sensitive to both fungicides (17\%), resistant to both fungicides $(67 \%)$, resistant only to thiophanate-methyl (14\%), and resistant only to vinclozolin (2\%). Isolates resistant to at least one fungicide were found in 33 of the 35 locations from which samples were taken. Disease incidences on geranium seedlings treated with $600 \mu \mathrm{g} / \mathrm{ml}$ of thiophanate-methyl and then inoculated with isolates sensitive and resistant to this fungicide were 1.4 and $96.1 \%$, respectively. Disease incidences on geranium seedlings treated with $600 \mu \mathrm{g} / \mathrm{ml}$ of vinclozolin and then inoculated with isolates sensitive and resistant to this fungicide were 0.3 and $91.9 \%$, respectively. With thiophanate-methyl, correlation coefficients $(r)$ between disease incidence and log $\mathrm{EC}_{50^{-}}$ germ or $\log \mathrm{EC}_{50}$-growth were 0.987 and 0.992 , respectively. With vinclozolin, correlation coefficients between disease incidence and $\log \mathrm{EC}_{50}$-germ and $\log \mathrm{EC}_{50}$-growth were 0.975 and 0.893 , respectively. Correlation coefficients between the two $\mathrm{EC}_{50}$ values for thiophanatemethyl were 0.989 and for vinclozolin were 0.900 . Isolates sensitive to thiophanate-methyl had a mean $\mathrm{EC}_{50^{-}}$germ value of $0.93 \mu \mathrm{g} / \mathrm{ml}$ and a $\mathrm{EC}_{50^{-}}$growth value of $0.11 \mu \mathrm{g} / \mathrm{ml}$. For isolates sensitive to vinclozolin the mean $\mathrm{EC}_{50}$-germ value was $1.63 \mu \mathrm{g} / \mathrm{ml}$ and the mean $\mathrm{EC}_{50}$-growth value was $0.26 \mu \mathrm{g} / \mathrm{ml}$. Thiophanate-methyl-resistant isolates had mean $\mathrm{EC}_{50^{-}}$germ and $\mathrm{EC}_{50^{-}}$ growth values greater than $500 \mu \mathrm{g} / \mathrm{ml}$ while vinclozolin-resistant isolates had a mean $\mathrm{EC}_{50}$-germ value greater than $500 \mu \mathrm{g} / \mathrm{ml}$ and a mean $\mathrm{EC}_{50^{-}}$growth value of $3.18 \mu \mathrm{g} / \mathrm{ml}$.

The production of ornamental crops in both greenhouses and nurseries has become one of the fastest-growing segments of agriculture in the United States. The estimated value of this industry in 1993 was over $\$ 6.1$ billion- $\$ 3.5$ billion and $\$ 2.6$ billion from the production of greenhouse and nursery crops, respectively (10). The ornamental horticulture industry is par-

Corresponding author: S. N. Jeffers

E-mail: sjffrs@clemson.edu

This research was supported in part by a grant (No. SL4455) from the Clemson University Research Grant Committee.

Technical Contribution No. 4445 of the South Carolina Agriculture and Forestry Research System, Clemson University.

Accepted for publication 8 March 1999.

Publication no. D-1999-0419-01R

(C) 1999 The American Phytopathological Society ticularly important to the economy and agriculture of the states in the Southeast, including South Carolina, where a large portion of the ornamental plants sold in the eastern United States originates. Botrytis cinerea Pers.:Fr. is a common and economically important pathogen of numerous greenhouse-grown ornamental crops $(5,14)$. Effective disease management usually requires sanitation and other cultural practices to avoid introducing the pathogen, manipulation of environmental conditions to discourage disease development, and fungicide applications to prevent or limit disease spread (14). Host resistance is not available for many popular greenhouse-grown ornamental crops (e.g., geranium, poinsettia, and gerbera). Therefore, fungicides traditionally have played an important role in managing leaf, stem, and flower blights in greenhouse production. However, resistance in populations of $B$. cinerea to the most commonly used classes of fungicides, the benzimidazoles and di- carboximides, has compromised their efficacy (3). Resistance to these fungicides complicates the management of diseases caused by $B$. cinerea and can lead to serious economic losses. Although benzimidazoles, such as thiophanate-methyl, have been the most widely used fungicides for control of many foliar pathogens in greenhouses, dicarboximides, such as vinclozolin, may be more important and effective for managing $B$. cinerea (10). In Pennsylvania greenhouses, over $90 \%$ of growers used benzimidazoles and more than $30 \%$ used dicarboximide fungicides (21).

Benzimidazole-resistant isolates are known to persist in populations of $B$. cinerea long after use of the fungicide has been discontinued $(11,18,19)$. Dicarboximideresistant isolates rarely were observed in nature in the years immediately after the introduction of dicarboximide fungicides in the mid-1970s; however, by the early 1980s, resistant isolates were common on several crops (20). Loss of efficacy of dicarboximides due to resistance was observed in vineyards in New Zealand (25), on greenhouse-grown cucumbers in Israel (38), and on strawberry plants in England (13). Isolates with moderate resistance to dicarboximides appeared to have fitness equal to sensitive isolates in greenhousegrown crops on Crete (26). In the absence of fungicides, dicarboximide-resistant subpopulations persisted within a predominantly sensitive population in one study (31); however, in another study, a predominantly dicarboximide-resistant population was supplanted over time by a sensitive one after successive inoculations of tomato fruit (12).

Various frequencies of fungicide-resistant isolates of $B$. cinerea have been found in surveys of numerous crops throughout the world, and isolates resistant to both benzimidazole and dicarboximide fungicides are not uncommon. In a recent survey of Connecticut greenhouses, nearly $75 \%$ of 45 isolates from greenhouse-grown crops were resistant to thiophanate-methyl and $43 \%$ were resistant to vinclozolin (17). Of 121 isolates collected from several crops in three European countries and Israel, 25\% were sensitive to both benzimidazole and dicarboximide fungicides, $32 \%$ were resistant to both, and $14 \%$ were benzimidazole-resistant and dicarboximide-sensitive (29). In 1988, $63 \%$ of isolates from greenhouse-grown tomatoes in England and Wales were benzimidazole-resistant (in- 
cluding $83 \%$ of the isolates from benzimidazole-treated tomato plants and $58 \%$ of the isolates from untreated plants) and $43 \%$ were dicarboximide-resistant (including $25 \%$ of the isolates from crops not treated with dicarboximides and $49 \%$ of the isolates from treated crops) (20). All dicarboximide-resistant isolates and $70 \%$ of the dicarboximide-sensitive isolates from greenhouses in Israel also were benzimidazole-resistant (16). In one strawberry field in Australia, $80 \%$ of the $B$. cinerea isolates were resistant to both the benzimidazole benomyl and the dicarboximide iprodione (34). The incidence of vinclozolin-resistant isolates of $B$. cinerea was high in greenhouses in Crete (26), and nearly all vinclozolin-resistant isolates also were benzimidazole-resistant. In addition, nearly all of the 281 dicarboximide-sensitive isolates also were benzimidazole-sensitive. In Spain in 1981 and 1982, 67\% of B. cinerea isolates collected from various crops in 67 greenhouses were dicarboximide-resistant (9). The Fungicide Resistance Action Committee (FRAC), an international group affiliated with the agrochemical industry, has called for comprehensive studies of the effectiveness of fungicides in order to satisfy growers' concerns for their crops worldwide (3).

This study was conducted to address two important issues concerning fungicideresistance in populations of $B$. cinerea on ornamental crops. The first objective was to determine the frequency of benzimidazole and dicarboximide resistance in populations of $B$. cinerea on ornamental crops in South Carolina greenhouses and relate these data to those from other regions. Despite the importance of the ornamental crop industry in the southeastern United States, no formal investigation has been conducted in this region to confirm patterns of resistance in populations of $B$. cinerea that are known to occur elsewhere. Results from a study such as this could have important implications on disease management recommendations for Botrytis blight on ornamental crops in the Southeast.

The second objective of this study was to evaluate and compare conidium germination and mycelium growth assays for determining fungicide sensitivity. Results from these two in vitro assays then could be correlated with those from an in vivo seedling assay to determine the accuracy of these methods for assessing fungicide sensitivity phenotypes of isolates of $B$. cinerea. Response of fungi to fungicides generally is reported as the effective concentration that inhibits conidium germination or mycelium growth by $50 \%$ $\left(\mathrm{EC}_{50}\right)$ on fungicide-amended medium. Sensitivity of $B$. cinerea to fungicides can differ depending on whether mycelium growth or conidium germination is assayed $(6,15,16,26)$. Therefore, the assay method used can affect the $\mathrm{EC}_{50}$ values calculated and reported. Both of these methods have been used previously to assay populations of $B$. cinerea for fungicide sensitivity $(6,7,15,16,21)$. Preliminary results of this study have been reported $(36,37)$.

\section{MATERIALS AND METHODS}

Isolation and maintenance of $B$. cinerea isolates. In 1996 and 1997, at least 10 samples of leaves, stems, bracts, or flowers of a number of common ornamental greenhouse crops (e.g., geranium, poinsettia, impatiens, and gerbera) were collected from each of 35 commercial greenhouses located throughout South Carolina. Plant parts exhibiting symptoms or signs of disease were detached from plants and placed in clean plastic bags and stored 1 to 2 days in an ice chest until they could be processed. In the laboratory, plant parts were placed in sterile glass Petri dishes containing Whatman No. 1 filter papers saturated with sterile distilled water. These moist chambers were placed on a laboratory bench $\left(22\right.$ to $\left.25^{\circ} \mathrm{C}\right)$ until conidia were observed-usually 1 to 3 days later. A small piece (approximately 2 by $2 \mathrm{~mm}$ ) of potato dextrose agar amended with $150 \mu \mathrm{g}$ chloramphenicol $/ \mathrm{ml}$ of medium $(\mathrm{PDA}+\mathrm{C})$ was taken from a Petri dish and, while looking through a dissecting microscope (10 to $20 \times$ ), touched to a conidiophore. The agar piece with adhering conidia was placed in the center of a Petri dish containing $\mathrm{PDA}+\mathrm{C}$ and incubated at $20^{\circ} \mathrm{C}$ in the dark. Two isolates from each plant organ were plated in this manner, although not every isolate grew to produce conidia. After 3 to 4 days, agar containing mycelium from the leading edge of the colony was transferred to the center of a disposable Petri dish (100 by $15 \mathrm{~mm}$ ) containing potato dextrose agar (PDA; Difco Laboratories, Detroit). Dishes were placed on a bench in the laboratory, where they were exposed daily to overhead fluorescent light and indirect natural light from a window. Conidia formed in the dishes in 10 to 14 days. Conidia were harvested from dishes by pipetting into dishes $3 \mathrm{ml}$ of a sterile, aqueous solution of $0.01 \%$ Tween 80 ; rubbing colonies gently with sterile bent glass rods; and transferring conidium suspensions by pipette into sterile glass culture tubes (13 by $100 \mathrm{~mm})$. An equal volume of sterile $30 \%$ glycerol in water was added to each tube, giving a final concentration of $15 \%$ glycerol. Suspensions of each isolate were transferred to several 2-ml cryogenic vials (Nalgene Corporation, Rochester, NY), and vials were stored in an ultra-lowtemperature freezer at $-80^{\circ} \mathrm{C}$. The final collection contained 131 pairs of isolates (with the two isolates in each pair recovered from conidia on two separate conidiophores attached to a single plant part) and 63 individual isolates (each of which was the only isolate collected from a given plant part). Therefore, a total of 325 isolates were stored.
To retrieve conidia of an isolate from vials stored at $-80^{\circ} \mathrm{C}$, a sterile wood applicator was dipped into a vial containing the conidium suspension and the attached viscous suspension (approximately $20 \mu \mathrm{l}$ ) was placed into a microcentrifuge tube containing $100 \mu \mathrm{l}$ of $0.01 \%$ Tween 80 solution. Vials were removed and returned to the ultra-low-temperature freezer rapidly enough to prevent suspensions from thawing completely. For each isolate, $20 \mu \mathrm{l}$ of resuspended conidia were put on PDA in a Petri dish, and dishes were placed on a laboratory bench for 10 to 14 days before harvesting the freshly produced conidia as described above. Concentrations of conidium suspensions were quantified by transferring $10 \mu \mathrm{l}$ of a suspension to $990 \mu \mathrm{l}$ of $0.01 \%$ Tween 80 and counting conidia with a hemacytometer. All conidium suspensions were standardized to 2 to $3 \times 10^{4}$ conidia/ml.

Fungicides. Commercial flowable formulations of thiophanate-methyl (46\% a.i., Cleary's 3336F; W. A. Cleary Corporation, Somerset, NJ) and vinclozolin (41.3\% a.i., Curalan; BASF Corporation, Research Triangle Park, NC) were used in all experiments. Fungicides were stored at $15^{\circ} \mathrm{C}$ in the dark to maintain and preserve fungicide activity.

Conidium germination assay. Dilutions of thiophanate-methyl and vinclozolin formulations were made with sterile distilled water to yield suspensions of 50,000 and $1,000 \mu \mathrm{g}$ of a.i./ml of each fungicide. A defined minimal medium, which was modified from the Difco Czapek-Dox recipe, was prepared and used to avoid possible interactions of fungicides with complex components of an undefined medium, such as PDA, that were observed in preliminary experiments. This medium (1 liter) contained $12 \mathrm{~g}$ of agar, $10 \mathrm{~g}$ of glucose, $3 \mathrm{~g}$ of $\mathrm{NaNO}_{3}, 1 \mathrm{~g}$ of $\mathrm{KH}_{2} \mathrm{PO}_{4}, 1 \mathrm{~g}$ of $\mathrm{K}_{2} \mathrm{HPO}_{4}, 0.5 \mathrm{~g}$ of $\mathrm{MgSO}_{4} \cdot 7 \mathrm{H}_{2} \mathrm{O}, 0.5 \mathrm{~g}$ of $\mathrm{KCl}$, and $0.01 \mathrm{~g}$ of $\mathrm{FeSO}_{4} \cdot 7 \mathrm{H}_{2} \mathrm{O}$; the final $\mathrm{pH}$ was 6.6. Erlenmeyer flasks, each containing a standard volume of medium and a magnetic stir bar, were autoclaved and allowed to cool to 55 to $60^{\circ} \mathrm{C}$. Appropriate volumes of stock fungicide suspensions were added to the medium to give final concentrations of $0.5,1,5,50$, and $500 \mu \mathrm{g}$ of a.i./ml of each fungicide. Additional flasks of medium without fungicides were used as controls. Media were dispensed into standard disposable Petri dishes (100 by $15 \mathrm{~mm}$ ) with $20 \mathrm{ml}$ of medium in each dish, or $1 \mathrm{ml}$ of medium into each well of 48-well tissue culture dishes ( 8 by 6 wells; CoStar, Cambridge, MA). The 48-well plates allowed eight isolates of $B$. cinerea to be assayed at each of the six fungicide concentrations (including control). Conidium suspensions were dispensed into each well in $10-\mu$ l aliquots. When Petri dishes were used, $10 \mu \mathrm{l}$ of conidium suspensions were pipetted onto the agar surface in discrete drops, allowing 
approximately 20 isolates to be assayed in each dish. All assays included three replications of each isolate per concentration, with replicates in separate dishes. Dishes were left open in a laminar-flow hood until the liquid of conidium suspensions was absorbed into the agar, and dishes were placed in the dark at $20^{\circ} \mathrm{C}$ for 14 to $18 \mathrm{~h}$ to allow conidia to germinate. Conidia then were fixed and stained with $0.025 \%$ aniline blue in 50\% lactic acid to stop growth and facilitate counting. Germination rate was determined by counting the number of conidia out of 100 that had germ tubeswith lengths at least three to four times the diameter of a conidium and a normal appearance-growing into the agar.

Mycelium growth assay. A total of 53 isolates representative of the 325-isolate collection were selected to compare the conidium germination and mycelium growth assays. Isolates came from 30 of the 35 greenhouses and represented all four phenotypes: 17 isolates were sensitive to both fungicides, 17 isolates were resistant to both, 16 isolates were resistant to thiophanate-methyl and sensitive to vinclozolin, and 3 isolates were sensitive to thiophanate-methyl and resistant to vinclozolin (only 3 isolates of this phenotype were available when the experiment was initiated). Isolates of the same phenotype were from different greenhouses. All 53 isolates were tested for germination of conidia as described above. These isolates also were tested for growth of mycelium on fungicide-amended medium. Minimal medium was amended with formulated thiophanatemethyl or vinclozolin to produce concentrations of $0,0.05,0.15,0.5,1.5,5$, and $500 \mu \mathrm{g}$ of a.i./ml and dispensed into disposable Petri dishes as described above. Agar plugs (5 $\mathrm{mm}$ in diameter) from the leading edge of cultures of the 53 isolates on PDA were placed in the center of Petri dishes containing unamended minimal medium. After 3 to 5 days in the dark at $20^{\circ} \mathrm{C}$, three $5-\mathrm{mm}$ plugs were selected randomly and were placed an equal distance apart on each of the concentrations of fungicide-amended medium. This process was replicated three times. Cultures were incubated at $20^{\circ} \mathrm{C}$ in the dark for 3 days. Mycelium growth was measured along a radius from the edge of the agar plug to the colony margin. Germination and growth assays of the 53 isolates were conducted twice.

Geranium seedling assay. To verify fungicide sensitivity phenotypes determined by conidium germination and mycelium growth, geranium seedlings were treated with fungicides and inoculated with the same 53 isolates of $B$. cinerea used in these in vitro assays. Geranium seeds (cv. Orbit, Light Salmon; Park Seed Co., Greenwood, SC) were sown in soilless container mix (Peat-Lite; Fafard, Inc., Anderson, SC) in 72-cell (12 by 6 cells) seedling trays in a greenhouse. When cotyledons expanded fully, approximately 10 to 14 days later, entire trays of geranium seedlings were sprayed with either water, thiophanate-methyl $(600 \mu \mathrm{g} / \mathrm{ml})$, or vinclozolin $(600 \mu \mathrm{g} / \mathrm{ml})$. Fungicide concentrations were based on label recommendations for greenhouse-grown ornamental crops. Fungicides and water were applied with hand-pumped, 500-ml sprayer bottles until cotyledons were thoroughly wet. Cotyledons were allowed to dry completely (approximately 1 to $2 \mathrm{~h}$ ) before preparing plants for inoculation.

Seedling trays with treated plants were cut to yield 12 six-cell strips. Each strip of six plants constituted a single replicate. One replicate from each of the three treatments was placed into an empty, intact 72cell seedling tray. Each set of treatments was used to assay one isolate; therefore, each seedling tray was used to assay four isolates. Each tray was placed on an inverted flat in a rectangular plastic tub that contained water $5 \mathrm{~cm}$ deep, and the tub was covered with a tight-fitting lid. This arrangement provided constant high relative humidity but prevented roots from becoming saturated.

To prepare inoculum, conidia were collected from PDA plates as described above and then were suspended in an aqueous solution of $0.1 \mathrm{M}$ glucose with $0.01 \%$ Tween $80(21,22)$. Conidium suspensions were quantified with a hemacytometer and standardized to a concentration of $1 \times 10^{6}$ conidia/ml for all isolates. Cotyledons on five of the six plants in each replicate strip were inoculated by dipping sterile, 6-mmdiameter filter-paper discs (Whatman No. 1) into a conidium suspension and placing one disc onto each cotyledon (30). One seedling in each replicate of all treatments was left uninoculated as an internal control and received discs dipped only in a solution of glucose plus Tween 80. Each treatment was replicated three times. Plastic tubs containing treated, inoculated plants were placed in a walk-in growth chamber with a 14-h photoperiod and a daily temperature range of 17 to $20^{\circ} \mathrm{C}$. Water from a hand-pumped spray bottle was misted over seedlings once per day for two days after inoculation to promote infection. Disease incidence was assessed 4 to 6 days after inoculation. Seedlings were scored 1.0 if both cotyledons had distinct lesions or signs of $B$. cinerea infection (usually profuse sporulation); seedlings with one diseased and one healthy cotyledon were scored 0.5 . The experiment was conducted twice.

Statistical analysis. Effective concentration values for germination $\left(\mathrm{EC}_{50}\right.$-germ) and mycelium growth $\left(\mathrm{EC}_{50}\right.$-growth) were calculated by fitting a dose-response function to a logistic model $(2,4)$. Tests based on the $t$ distribution of the mean of slopes of dose-response curves, with $P=0.05$, were performed for each isolate to determine if data sets from repeated trials could be combined (28). Formulas to calculate $\mathrm{EC}_{50}$ values and $t$-distribution statistics were written into the formula function of Excel 7.0 (Microsoft Corporation, Redmond, WA). Correlation coefficients $(r)$ between pairs of response variables also were calculated with the correlation function in Excel 7.0. For in vitro assays, $\mathrm{EC}_{50}$ values were transformed to $\log _{10}$ values before analyses; for plant assays, percentages were transformed to arcsine-square root values before analyses (28).

\section{RESULTS}

In 1996 and 1997, 325 isolates of B. cinerea were collected from ornamental crops in 35 commercial greenhouses in 16 counties around South Carolina (Table 1, Fig. 1). Of these 325 isolates, 131 pairs of isolates were each collected from a common piece of plant tissue. Of these 131 pairs, the two individual isolates in 94 pairs exhibited a common fungicide sensitivity phenotype, and the isolates in 37 pairs differed in phenotype. Because of the difference between isolates within pairs, all 325 isolates were treated as distinct and independent throughout this study. Isolates of $B$. cinerea were collected at 34 of 35 sites; only one greenhouse in Colleton County did not yield any isolates. Resistant isolates were common and widespread. Isolates resistant to at least one of the two fungicides were found in 32 of the greenhouses $(91 \%)$. Isolates sensitive to both fungicides were found in 23 greenhouses $(66 \%)$; isolates resistant to both fungicides were present in 30 greenhouses (86\%); isolates resistant to only thiophanatemethyl were found in 20 greenhouses (57\%); and isolates resistant to only vinclozolin were present in just 5 greenhouses $(14 \%)$. Only one isolate was collected at two of the greenhouses (greenhouses MC and GA; Table 1 and Fig. 1); both of these isolates were sensitive to both fungicides. At 11 sites, none of the isolates collected were sensitive to both thiophanate-methyl and vinclozolin, and all isolates collected at 5 of these 11 greenhouses were resistant to both fungicides.

$B$. cinerea was isolated from an array of ornamental crops but predominantly from begonia, geranium, gerbera, impatiens, petunia, and poinsettia. Greenhouses where isolates were collected ranged from small, family-run operations supplying plants for local retail stores to large growers with regional distribution. Most greenhouses used a large portion of their space for bedding plant production, but three operations were dedicated solely to growing herbs organically from seed (i.e., without the use of chemical pesticides; greenhouses $\mathrm{CH}$, PP, and MC; Table 1 and Fig. 1). In most greenhouses, fungicides for foliar disease management included many commonly used products (e.g., thiophanate-methyl, vinclozolin, iprodione, chlorothalonil, and copper products), but these fungicides 


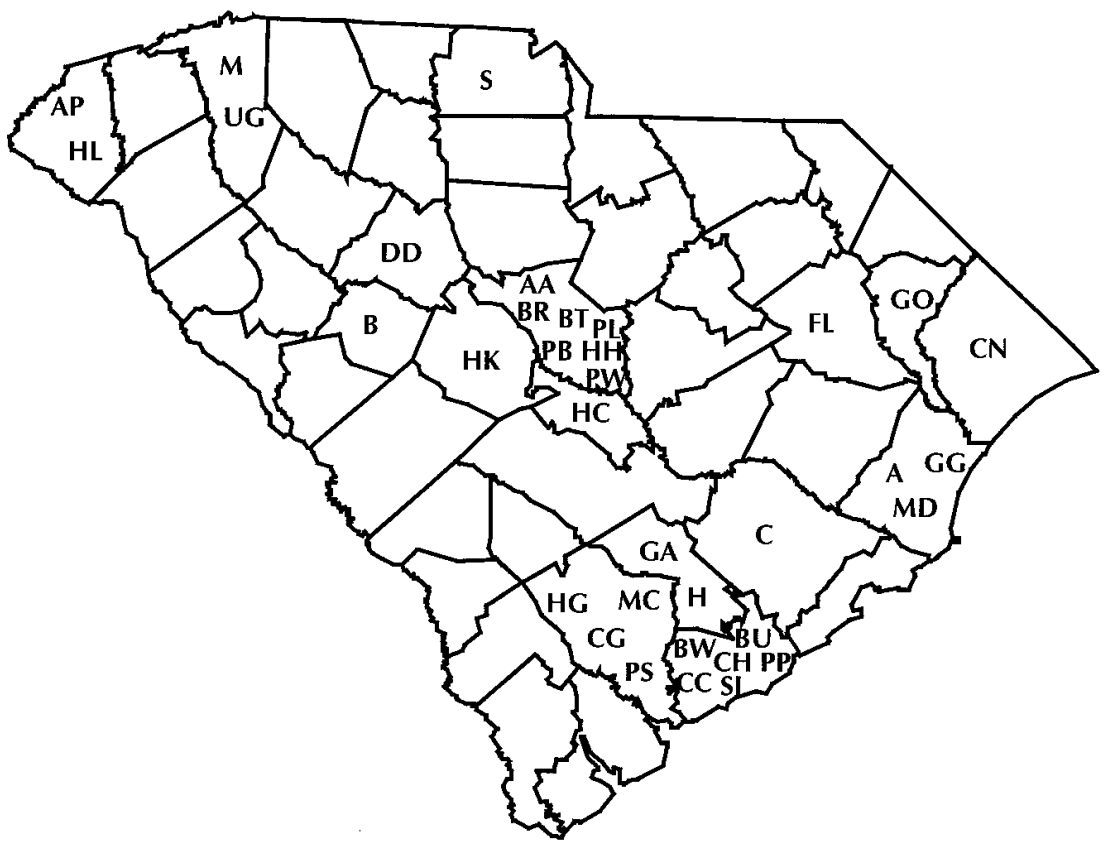

Fig. 1. Locations of 35 commercial greenhouses in South Carolina from which isolates of Botrytis cinerea were collected from ornamental crops in 1996 and 1997. Letters represent individual greenhouses.

Table 1. Number of isolates of Botrytis cinerea in each of four fungicide-sensitivity phenotypes collected from ornamental crops at 35 greenhouses around South Carolina in 1996 and 1997

\begin{tabular}{|c|c|c|c|c|c|c|}
\hline \multirow[b]{2}{*}{ County } & \multirow[b]{2}{*}{ Greenhouse $^{b}$} & \multicolumn{5}{|c|}{ Phenotype $^{a}$} \\
\hline & & $\mathbf{S}^{\mathrm{T}} \mathbf{S}^{\mathbf{V}}$ & $\mathbf{R}^{\mathrm{T}} \mathbf{R}^{\mathbf{V}}$ & $\mathbf{R}^{\mathrm{T}} \mathbf{S}^{\mathbf{V}}$ & $\mathbf{S}^{\mathrm{T}} \mathbf{R}^{\mathbf{V}}$ & Total \\
\hline Berkeley & $\mathrm{C}$ & 1 & 0 & 3 & 0 & 4 \\
\hline Calhoun & $\mathrm{HC}$ & 1 & 8 & 0 & 0 & 9 \\
\hline \multirow[t]{6}{*}{ Charleston } & $\mathrm{BU}$ & 0 & 8 & 1 & 0 & 9 \\
\hline & BW & 1 & 5 & 2 & 0 & 8 \\
\hline & $\mathrm{CC}$ & 1 & 9 & 1 & 1 & 12 \\
\hline & $\mathrm{CH}$ & 4 & 1 & 3 & 1 & 9 \\
\hline & PP & 8 & 0 & 2 & 0 & 10 \\
\hline & SI & 0 & 7 & 0 & 0 & 7 \\
\hline \multirow[t]{4}{*}{ Colleton } & HG & 0 & 0 & 0 & 0 & 0 \\
\hline & CG & 3 & 3 & 0 & 0 & 6 \\
\hline & MC & 1 & 0 & 0 & 0 & 1 \\
\hline & PS & 0 & 6 & 1 & 0 & 7 \\
\hline \multirow[t]{2}{*}{ Dorchester } & GA & 1 & 0 & 0 & 0 & 1 \\
\hline & $\mathrm{H}$ & 4 & 6 & 1 & 1 & 12 \\
\hline Florence & FL & 1 & 19 & 0 & 0 & 20 \\
\hline \multirow[t]{3}{*}{ Georgetown } & A & 3 & 8 & 3 & 2 & 16 \\
\hline & GG & 0 & 10 & 1 & 0 & 11 \\
\hline & MD & 2 & 7 & 0 & 0 & 9 \\
\hline \multirow[t]{2}{*}{ Greenville } & $\mathrm{M}$ & 0 & 5 & 0 & 0 & 5 \\
\hline & UG & 1 & 6 & 0 & 0 & 7 \\
\hline Horry & $\mathrm{CN}$ & 2 & 2 & 0 & 0 & 4 \\
\hline Lexington & HK & 0 & 9 & 2 & 0 & 11 \\
\hline Marion & GO & 2 & 6 & 2 & 0 & 10 \\
\hline Newberry & DD & 5 & 3 & 3 & 0 & 11 \\
\hline \multirow[t]{2}{*}{ Oconee } & AP & 1 & 4 & 0 & 0 & 5 \\
\hline & HL & 2 & 2 & 2 & 0 & 6 \\
\hline \multirow[t]{7}{*}{ Richland } & PL & 3 & 5 & 4 & 0 & 12 \\
\hline & BR & 0 & 4 & 0 & 0 & 4 \\
\hline & AA & 0 & 5 & 0 & 0 & 5 \\
\hline & PB & 0 & 18 & 1 & 0 & 19 \\
\hline & PW & 0 & 17 & 0 & 0 & 17 \\
\hline & BT & 2 & 3 & 2 & 1 & 8 \\
\hline & $\mathrm{HH}$ & 3 & 15 & 2 & 0 & 20 \\
\hline Saluda & B & 5 & 9 & 5 & 0 & 19 \\
\hline York & S & 0 & 7 & 4 & 0 & 11 \\
\hline Total & 35 & 57 & 217 & 45 & 6 & 325 \\
\hline
\end{tabular}

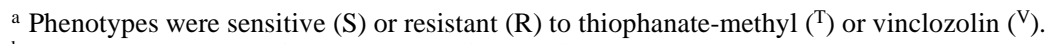

${ }^{\mathrm{b}}$ Arbitrary designation for greenhouses from which samples were taken. usually were not applied on a regular schedule.

Conidium germination assays were conducted on all isolates, and $\mathrm{EC}_{50^{-}}$germ values were determined (Table 2). Isolates exhibiting abnormal or no conidium germination when exposed to concentrations of $\leq 5 \mu \mathrm{g} / \mathrm{ml}$ of thiophanate-methyl or vinclozolin were considered sensitive $\left(\mathrm{S}^{\mathrm{T}}\right.$ and $\mathrm{S}^{\mathrm{V}}$, respectively). Isolates exhibiting normal germination when fungicide concentrations were $>5 \mu \mathrm{g} / \mathrm{ml}$ were designated resistant to thiophanate-methyl or vinclozolin $\left(\mathrm{R}^{\mathrm{T}}\right.$ and $\mathrm{R}^{\mathrm{V}}$, respectively). Of the 325 isolates collected, $63(19 \%)$ were sensitive to thiophanate-methyl while 102 isolates $(31 \%)$ were sensitive to vinclozolin. Only 57 isolates $(17 \%)$ were sensitive to both fungicides $\left(\mathrm{S}^{\mathrm{T}} \mathrm{S}^{\mathrm{V}}\right)$, whereas the majority, 217 isolates $(67 \%)$, were resistant to both fungicides $\left(\mathrm{R}^{\mathrm{T}} \mathrm{R}^{\mathrm{V}}\right)$. Isolates sensitive to one fungicide but resistant to the other were less common; 45 isolates (14\%) were resistant to thiophanate-methyl and sensitive to vinclozolin $\left(\mathrm{R}^{\mathrm{T}} \mathrm{S}^{\mathrm{V}}\right)$, and only 6 isolates (2\%) were sensitive to thiophanate-methyl and resistant to vinclozolin $\left(\mathrm{S}^{\mathrm{T}} \mathrm{R}^{\mathrm{V}}\right)$. Isolates sensitive to thiophanate-methyl differed in degree of sensitivity expressed; $49 \%$ (31/63) were sensitive at $<0.5 \mu \mathrm{g} / \mathrm{ml}, 29 \%$ $(18 / 63)$ were sensitive in the range of 0.5 to $1.0 \mu \mathrm{g} / \mathrm{ml}$, and $22 \%(14 / 63)$ had $\mathrm{EC}_{50^{-}}$ germ values $>1$ and $\leq 5 \mu \mathrm{g} / \mathrm{ml}$. In contrast, $84 \%(86 / 102)$ of vinclozolin-sensitive isolates had $\mathrm{EC}_{50}$-germ values in the range of 1 to $5 \mu \mathrm{g} / \mathrm{ml}, 16 \%(16 / 102)$ were sensitive between 0.5 and $1.0 \mu \mathrm{g} / \mathrm{ml}$, and no isolates were sensitive to vinclozolin at $<0.5 \mu \mathrm{g} / \mathrm{ml}$. The germination of most of the isolates resistant to thiophanate-methyl $(81 \%$ or $213 / 262)$ or vinclozolin $(85 \%$ or $190 / 223$ ) was unaffected by the highest concentration of fungicides tested (i.e., $500 \mu \mathrm{g} / \mathrm{ml}$ ).

To compare different methods of assessing sensitivity to fungicides, 53 of the 325 isolates of $B$. cinerea were evaluated further. Germination of conidia and growth of mycelia on fungicide-amended agar medium were compared. Experiments were conducted twice and were not statistically different; therefore, data were pooled. Phenotypes of individual isolates determined by conidium germination and mycelium growth assays were comparable; however, the ranges of $\mathrm{EC}_{50}$ values used to determine phenotypes from the two methods were different, especially when isolates were exposed to vinclozolin (Table 3 ). The mean $\mathrm{EC}_{50}$ value for isolates sensitive to thiophanate-methyl $\left(\mathrm{S}^{\mathrm{T}}\right)$ was $0.9 \mu \mathrm{g} / \mathrm{ml}$ for germination and $0.1 \mu \mathrm{g} / \mathrm{ml}$ for mycelium growth. The mean $\mathrm{EC}_{50}$ value for vinclozolin-sensitive isolates $\left(\mathrm{S}^{\mathrm{V}}\right)$ was $1.6 \mu \mathrm{g} / \mathrm{ml}$ for germination and $0.3 \mu \mathrm{g} / \mathrm{ml}$ for mycelium growth. Isolates were considered sensitive to thiophanate-methyl and vinclozolin when $\mathrm{EC}_{50^{-}}$germ was $\leq 5 \mu \mathrm{g} / \mathrm{ml}$ or when $\mathrm{EC}_{50}$-growth was $\leq 1 \mu \mathrm{g} / \mathrm{ml}$.

All isolates resistant to thiophanatemethyl were unaffected in both germina- 
tion and growth by the highest concentration of thiophanate-methyl used (500 $\mu \mathrm{g} / \mathrm{ml}$ ), and the $\mathrm{EC}_{50}$ values for both assay methods were comparable. However, sensitivity of vinclozolin-resistant isolates depended on the assay used. The mean $\mathrm{EC}_{50}$ value for conidium germination was $>500 \mu \mathrm{g} / \mathrm{ml}$, whereas the mean $\mathrm{EC}_{50}$ value for mycelium growth was $3.2 \mu \mathrm{g} / \mathrm{ml}$.

Inoculation of geranium seedlings treated with fungicides or water confirmed phenotypes determined by conidium germination or mycelium growth assays. Seedlings treated with water and then inoculated with sensitive isolates consistently became diseased ( 92 to $99 \%$ disease incidence; Table 3). There was no apparent difference in virulence between sensitive and resistant isolates on these control plants. Seedlings treated with fungicides at label rates and then inoculated with sensitive isolates were protected from infection ( 0 to $2 \%$ disease incidence), whereas those inoculated with resistant isolates were not protected and readily became diseased (91 to $98 \%$ disease incidence).

Similarities among the two in vitro assay methods and the geranium seedling assay were examined by calculating correlation coefficients between pairs of assays for the 53 isolates (Table 3). When thiophanatemethyl was used, results between all pairs of the three assays were highly correlated $(r=0.99)$. When vinclozolin was used, results from the conidium germination and the seedling assays were highly correlated

Table 2. Sensitivities and phenotypes of 325 isolates of Botrytis cinerea to thiophanate-methyl and vinclozolin based on $\mathrm{EC}_{50}$ values for germination of conidia on fungicide-amended medium ${ }^{\mathrm{a}}$

\begin{tabular}{|c|c|c|c|c|c|c|c|c|}
\hline \multirow{2}{*}{$\begin{array}{l}\mathrm{EC}_{50}(\mu \mathrm{g} / \mathrm{ml}) \text { range for } \\
\text { thiophanate-methyl }\end{array}$} & \multicolumn{8}{|c|}{$\mathrm{EC}_{50}(\mu \mathrm{g} / \mathrm{ml})$ range for vinclozolin } \\
\hline & $<0.5$ & $0.5-1$ & $>1-5$ & $>5-10$ & $>10-50$ & $>50-100$ & $>100-500$ & $>500$ \\
\hline$<0.5$ & $0^{\mathrm{b}}$ & 1 & 29 & 0 & 0 & 0 & 0 & 1 \\
\hline $0.5-1$ & 0 & 1 & 13 & 0 & 0 & 0 & 0 & 4 \\
\hline \multirow[t]{2}{*}{$>1-5$} & 0 & 4 & 9 & 0 & 0 & 0 & 0 & 1 \\
\hline & \multicolumn{3}{|c|}{$\mathrm{S}^{\mathrm{T}} \mathrm{S}^{\mathrm{V}}$ total $=57(17 \%)^{\mathrm{c}}$} & \multicolumn{5}{|c|}{$\mathrm{S}^{\mathrm{T}} \mathrm{R}^{\mathrm{V}}$ total $=6(2 \%)$} \\
\hline$>5-10$ & 0 & 0 & 0 & 0 & 0 & 0 & 0 & 0 \\
\hline$>10-50$ & 0 & 0 & 1 & 0 & 0 & 1 & 2 & 9 \\
\hline$>50-100$ & 0 & 0 & 0 & 0 & 0 & 1 & 2 & 8 \\
\hline$>100-500$ & 0 & 0 & 4 & 0 & 2 & 4 & 8 & 7 \\
\hline \multirow[t]{2}{*}{$>500$} & 0 & 10 & 30 & 0 & 2 & 2 & 9 & 160 \\
\hline & \multicolumn{3}{|c|}{$\mathrm{R}^{\mathrm{T}} \mathrm{S}^{\mathrm{V}}$ total $=45(14 \%)$} & \multicolumn{5}{|c|}{$\mathrm{R}^{\mathrm{T}} \mathrm{R}^{\mathrm{V}}$ total $=217(67 \%)$} \\
\hline
\end{tabular}

${ }^{\mathrm{a}} \mathrm{EC}_{50}$ values, the effective concentrations that inhibited conidium germination by $50 \%$, were calculated from percentages of conidia of each isolate that germinated on a defined medium amended with $0,0.5,1,5,50$, and $500 \mu \mathrm{g} / \mathrm{ml}$ of thiophanate-methyl or vinclozolin.

${ }^{\mathrm{b}}$ Numbers of isolates in each category of fungicide sensitivity.

c Total numbers of isolates (and corresponding percentages out of 325) that were classified into four phenotypes based on resistance $(\mathrm{R})$ or sensitivity $(\mathrm{S})$ to thiophanate-methyl $\left({ }^{\mathrm{T}}\right)$ and vinclozolin $\left({ }^{\mathrm{V}}\right)$.
( $r=0.98)$; results between the conidium germination and mycelium growth assays and between the mycelium growth and seedling assays were not as highly correlated ( $r=0.90$ and 0.89 , respectively).

\section{DISCUSSION}

Resistance to two of the most popular fungicides in the ornamental crop industry (10) was common and widespread in populations of $B$. cinerea in commercial greenhouses throughout South Carolina. Resistance to both the benzimidazole thiophanate-methyl and the dicarboximide vinclozolin $\left(\mathrm{R}^{\mathrm{T}} \mathrm{R}^{\mathrm{V}}\right)$ was the most common phenotype found among the 325 isolates from ornamental crops, accounting for $67 \%$ of all isolates collected. The high incidence of resistance to both fungicides was similar to that reported for other greenhouse populations of $B$. cinerea around the world $(16,17,21,26,29)$. Considering the frequent and long-time use of both thiophanate-methyl and vinclozolin in greenhouses $(10,21)$ and the presumed stability of mutations conferring benzimidazole resistance and possibly dicarboximide resistance $(6,7,15,16,21)$, it is not surprising that resistance to both fungicides was so prevalent. These fungicides had not been used either frequently, consistently, or at all in several of the greenhouse operations in this study; yet resistant isolates were found in all but a few locations. The method of collecting isolates from diseased plant material leaves open the possibility of clonal relationships between isolates collected from the same greenhouse. However, when two isolates per plant part were collected from 131 different pieces of diseased plants, the two isolates in 37 (28\%)

Table 3. Comparison of 53 isolates of Botrytis cinerea with different fungicide-sensitivity phenotypes based on $\mathrm{EC}_{50}$ values for conidium germination and mycelium growth on fungicide-amended medium and disease incidence on geranium seedlings treated with fungicides or water

\begin{tabular}{|c|c|c|c|c|c|c|c|c|}
\hline \multirow[b]{3}{*}{ Phenotype $^{c}$} & \multirow[b]{3}{*}{ No. of isolates } & \multicolumn{4}{|c|}{$\mathrm{EC}_{50}(\mu \mathrm{g} / \mathrm{ml})^{\mathrm{a}}$} & & & \\
\hline & & \multicolumn{2}{|c|}{ Thiophanate-methyl } & \multicolumn{2}{|c|}{ Vinclozolin } & \multicolumn{3}{|c|}{ Disease incidence $(\%)^{\mathrm{b}}$} \\
\hline & & Germination & Growth & Germination & Growth & Thiophanate- methyl & Vinclozolin & Water \\
\hline$\overline{\mathrm{S}^{\mathrm{T}} \mathrm{S}^{\mathrm{V}}}$ & 17 & $1.0(0.6)^{\mathrm{d}}$ & $0.1(0.1)$ & $1.9(0.9)$ & $0.3(0.1)$ & $1.7(2.3)$ & $0.4(0.9)$ & $92.4(7.1)$ \\
\hline $\mathrm{R}^{\mathrm{T}} \mathrm{R}^{\mathrm{V}}$ & 17 & $>500(0)$ & $>500(0)$ & $>500(0)$ & $3.4(5.2)$ & $97.9(3.6)$ & $90.8(14.5)$ & $97.2(3.3)$ \\
\hline $\mathrm{R}^{\mathrm{T}} \mathrm{S}^{\mathrm{V}}$ & 16 & $>500(0)$ & $>500(0)$ & $1.3(0.6)$ & $0.3(0.1)$ & $94.2(8.5)$ & $0.2(0.6)$ & $94.7(7.9)$ \\
\hline$S^{\mathrm{T}} \mathrm{R}^{\mathrm{V}}$ & 3 & $0.6(0.3)$ & $0.1(0.1)$ & $>500(0)$ & $1.9(0.2)$ & $0(0)$ & $98.3(2.9)$ & $98.9(1.9)$ \\
\hline $\mathrm{S}^{\mathrm{T}}$ & 20 & $0.9(0.6)$ & $0.1(0.1)$ & $\ldots$ & $\ldots$ & $1.4(2.2)$ & $\ldots$ & $93.4(7.0)$ \\
\hline $\mathrm{R}^{\mathrm{T}}$ & 33 & $>500(0)$ & $>500(0)$ & 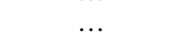 & & $96.1(6.6)$ & & $96.0(6.1)$ \\
\hline $\mathrm{S}^{\mathrm{V}}$ & 33 & $\ldots$ & $\ldots$ & $1.6(0.8)$ & $0.3(0.1)$ & $\ldots$ & $0.3(0.8)$ & $93.5(7.5)$ \\
\hline \multirow[t]{3}{*}{$\mathrm{R}^{\mathrm{V}}$} & 20 & $\ldots$ & $\ldots$ & $>500(0)$ & $3.2(4.8)$ & $\ldots$ & $91.9(13.6)$ & $97.4(3.2)$ \\
\hline & & & & \multicolumn{3}{|c|}{ Correlation coefficients $(r)^{\mathrm{e}}$} & & \\
\hline & & & & Thiophan & methyl & Vinclozolin & & \\
\hline \multirow{3}{*}{\multicolumn{4}{|c|}{$\begin{array}{l}\log _{10}\left(E_{50} \text {-germ }\right) \text { versus } \log _{10}\left(E_{50} \text {-growth }\right) \\
\log _{10}\left(E_{50^{-}} \text {-germ }\right) \text { versus disease incidence } \\
\log _{10}\left(E_{50} \text {-growth }\right) \text { versus disease incidence }\end{array}$}} & \multicolumn{2}{|c|}{0.99} & 0.90 & & \\
\hline & & & & \multicolumn{2}{|c|}{0.99} & 0.98 & & \\
\hline & & & & \multicolumn{2}{|c|}{0.99} & 0.89 & & \\
\hline
\end{tabular}

${ }^{\mathrm{a}} \mathrm{EC}_{50}$ values are the effective concentrations of fungicide that inhibited conidium germination or mycelium growth by $50 \%$.

${ }^{\mathrm{b}}$ Mean percentage of geranium seedlings that became diseased. Cotyledons were inoculated with isolates of $B$. cinerea (see text); six seedlings constituted a replicate and three replicates were used per isolate. Replicates were treated with water or $600 \mu \mathrm{g} / \mathrm{ml}$ of thiophanate-methyl or vinclozolin prior to inoculation.

${ }^{\mathrm{c}}$ Isolates were classified as sensitive (S) or resistant $(\mathrm{R})$ to thiophanate-methyl $\left({ }^{\mathrm{T}}\right)$ or vinclozolin $\left({ }^{\mathrm{V}}\right)$. Isolates were resistant if $\mathrm{EC}_{50} \mathrm{values}$ for germination or growth were $>5 \mu \mathrm{g} / \mathrm{ml}$ or $>1 \mu \mathrm{g} / \mathrm{ml}$, respectively.

d Values are means and standard deviations (in parentheses).

${ }^{\mathrm{e}}$ Correlation coefficients between pairs of response variables for each fungicide using all 53 isolates. 
of the pairs exhibited a different phenotype. This suggests that diverse and nonuniform populations of $B$. cinerea exist in close proximity on diseased host plants or that dynamic shifts in genotypes within populations have occurred in situ.

Benzimidazole resistance has been reported to be the result of one or a few stable mutations in the genome (35) and resistance to benzimidazoles does not appear to compromise the fitness of $B$. cinerea isolates to infect a host or reproduce $(11,19,27)$. Consequently, benzimidazoleresistant populations have persisted even in areas where applications of these fungicides have not occurred for several years (18). Virulence of isolates resistant to thiophanate-methyl was similar to that of sensitive isolates in our geranium bioassay. Similarly, dicarboximide-resistant isolates were as virulent on vinclozolin-treated and -untreated geraniums as sensitive isolates were on untreated geraniums. These observations are consistent with reports that dicarboximide-resistant and -sensitive isolates were competitive and virulent $(16,21,23,32)$ but contrast with studies that suggest dicarboximide-resistant isolates were less virulent than sensitive ones $(6,12,15)$. In French vineyards, dicarboximide-resistant populations from some regions of the country were as virulent as sensitive ones, while those in other regions were not as virulent (18).

Reliable records of fungicide application in the greenhouses visited were not available; therefore, prior fungicide use could not be compared to incidence of resistant isolates. In other studies, however, no correlation was found between frequency of benzimidazole-resistant isolates and prior use of benzimidazole fungicides $(1,24)$. In addition, resistance was found not to be correlated with prior use of either benzimidazole or dicarboximide fungicides in Connecticut greenhouses (17). Other studies indicated that dicarboximide resistance was highly correlated with more than three or four dicarboximide applications per year $(1,20)$.

Our findings were consistent with those of others, in that a high percentage of isolates resistant to dicarboximides also were resistant to benzimidazoles even among populations where there was no record of previous benzimidazole exposure (26) or where benzimidazoles had not been used for several years (18). Long-time or excessive use of these fungicides, the stability of fungicide-resistant isolates in populations, and the possible movement of resistant isolates on plant material from propagation greenhouses to local production greenhouses might explain this pattern, as Moorman and Lease have suggested previously (21). In addition, Hisada et al. (12) suggested that dicarboximide resistance may be acquired more easily by benzimidazole-resistant isolates than by benzimidazole-sensitive ones. More benzimida- zole-resistant phenotypes have been observed in studies of dicarboximide-resistant populations than in dicarboximidesensitive populations $(1,12,16,26)$. Our finding that $67 \%$ of isolates were resistant to both fungicides $\left(\mathrm{R}^{\mathrm{T}} \mathrm{R}^{\mathrm{V}}\right)$ and only $14 \%$ resistant to thiophanate-methyl but sensitive to vinclozolin $\left(\mathrm{R}^{\mathrm{T}} \mathrm{S}^{\mathrm{V}}\right)$ is consistent with this hypothesis. Similarly, only $2 \%$ of the isolates in our collection were sensitive to thiophanate-methyl and resistant to vinclozolin $\left(S^{T} R^{V}\right)$. In contrast, Wang et al. did not find a correlation between dicarboximide and benzimidazole resistant isolates (33).

Thus far, genetic investigations have not demonstrated cross-resistance between the two fungicide groups. Studies with Botryotinia fuckeliana (teleomorph of B. cinerea; 7,8 ) have suggested independence and probable linkage, based on a distance of approximately 47 map units, of the two major genes conferring benzimidazole and dicarboximide resistance, $M b c 1$ and Daf1, respectively. The genetic mechanism conferring benzimidazole resistance has detailed the specific amino acid substitutions and codon positions (35), but a mechanism for resistance to dicarboximides remains incomplete.

Both methods of determining fungicide sensitivity in vitro (i.e., conidium germination and mycelium growth) were correlated with disease incidence on fungicidetreated geranium seedlings. Therefore, either method is acceptable for isolate testing and phenotype designation; although with vinclozolin, correlation was highest between conidium germination and disease incidence. All isolates were virulent on water-treated plants regardless of phenotype. Northover (23) suggested that germination assays gave a more reliable estimate of resistance, especially when comparing dicarboximide (iprodione) and benzimidazole (benomyl) fungicides, and a lower estimate of the percentage of the population sensitive to either benomyl or iprodione. Germination assays also may reduce erroneous phenotype designations for genetically unstable sensitive isolates that produce mutant sectors of mycelium, which may be difficult to distinguish or interpret $(15,18)$.

Conidia of sensitive isolates were affected by low concentrations of both fungicides $(\leq 5 \mu \mathrm{g} / \mathrm{ml})$, and inhibition of germination was apparent upon exposure to fungicide-amended medium after 14 to 18 $\mathrm{h}$ of incubation. However, germinating conidia responded to benzimidazole and dicarboximide fungicides differently. Conidia of sensitive isolates exposed to critical concentrations of thiophanatemethyl produced stunted and distorted germ tubes (1). Conidia of sensitive isolates exposed to vinclozolin produced no germ tubes and no discernible signs of germ-tube initiation. Germ tubes and resulting hyphae from resistant isolates ex- posed to thiophanate-methyl or vinclozolin appeared normal and were not obviously different from those of sensitive or resistant isolates grown on a medium without fungicides. Unlike the results reported by Davis et al., we observed no bursting of conidia on dicarboximide-amended medium (6).

Conidia and mycelia were differentially sensitive to both fungicides, especially dicarboximides, which is consistent with other reports $(6,15,16,26)$. As such, $\mathrm{EC}_{50}$ values are more meaningful when associated with the assay method used to derive the values. For isolates sensitive to both fungicides, mycelium growth was affected at lower concentrations than was conidium germination; therefore, $\mathrm{EC}_{50}$ values for mycelium growth were lower than those for conidium germination. A similar situation occurred with isolates resistant to vinclozolin. However, for isolates resistant to thiophanate-methyl, both mycelia and conidia were unaffected by a thiophanatemethyl concentration of $500 \mu \mathrm{g} / \mathrm{ml}$.

Results of fungicide sensitivity assays in this study were consistent with those reported by others. Katan (16) reported vinclozolin-resistant and -sensitive isolates with $\mathrm{EC}_{50}$-growth values ranging from 1 to $4.9 \mu \mathrm{g} / \mathrm{ml}$ and 0.1 to $0.3 \mu \mathrm{g} / \mathrm{ml}$, respectively. In another study, isolates were considered sensitive to benomyl when $\mathrm{EC}_{50^{-}}$ growth was $<1 \mu \mathrm{g} / \mathrm{ml}$, while isolates highly resistant to benomyl had $\mathrm{EC}_{50}$-growth values that were $>100 \mu \mathrm{g} / \mathrm{ml}$ (7). In the same study, vinclozolin-sensitive isolates had $\mathrm{EC}_{50}$-growth values $<1 \mu \mathrm{g} / \mathrm{ml}$, while isolates resistant to vinclozolin had a range of $\mathrm{EC}_{50}$-growth values from 3 to $>100 \mu \mathrm{g} / \mathrm{ml}$. By this standard, the majority of resistant isolates in our collection exhibited high resistance to thiophanate-methyl and low resistance to vinclozolin.

In this study, we found that the two in vitro assays, one based on conidium germination and the other based on mycelium growth, determined a similar phenotype for individual isolates and that results from both assays were highly correlated with those from a geranium seedling assay. Regardless of differences in degrees of sensitivity and resistance in laboratory assays, the real test is the capacity of a fungicide to protect plants against the pathogen population present in the field. Both in vitro assays were effective at predicting disease occurrence on geranium seedlings in the presence of thiophanate-methyl or vinclozolin.

Also in this study, we identified high frequencies of benzimidazole and dicarboximide resistance in populations of $B$. cinerea associated with greenhouse-grown ornamental crops in South Carolina. Similar situations previously have been reported for greenhouse-grown ornamental crops in other parts of the country $(17,21)$. Consequently, fungicide resistance appears to be a widespread problem in the industry 
in the United States. Based on the low incidence of isolates still sensitive to these fungicides, recommendations for managing Botrytis blight on ornamental crops in greenhouses should de-emphasize the use of thiophanate-methyl, vinclozolin, and chemically related compounds. Greenhouse operators in Pennsylvania currently are advised not to use benzimidazole fungicides for management of Botrytis diseases (21). Management strategies for Botrytis blight should focus on integrated disease management $(5,14)$, including the use of fungicides. Growers no longer can rely on benzimidazole and dicarboximide fungicides as primary management tools.

\section{ACKNOWLEDGMENTS}

We thank Park Seed Co. for the generous donation of geranium seed; W. A. Cleary Chemical Corporation and BASF Corporation for providing fungicides; Fafard, Inc. for providing container mix used in seedling experiments; M. J. Sherwood and R. B. Baker for technical support; and W. V. Baird, R. A. Dean, and E. I. Zehr for reviewing the manuscript.

\section{LITERATURE CITED}

1. Beever, R. E., Laracy, E. P., and Pak, H. A. 1989. Strains of Botrytis cinerea resistant to dicarboximide and benzimidazole fungicides in New Zealand vineyards. Plant Pathol. 38:427-437.

2. Berkson, J. 1951. Why I prefer logits to probits. Biometrics 7:327-339.

3. Brent, K. J. 1995. Fungicide resistance in crop pathogens: How can it be managed? FRAC Monograph No. 1. Int. Group Natl. Assoc. Manfactur. Agrochem. Prod. (GIFAP), Brussels.

4. Chatterjee, S., and Price, B. 1991. Regression Analysis by Example, 2nd Edition. John Wiley \& Sons, Inc., New York.

5. Daughtrey, M. L., Wick, R. L., and Peterson, J. L. 1995. Compendium of flowering potted plant diseases. APS Press, St. Paul, MN.

6. Davids, R. P., and Dennis, C. 1981. Properties of dicarboximide-resistant strains of Botrytis cinerea. Pestic. Sci. 12:521-535.

7. Faretra, F., and Pollastro, S. 1991. Genetic basis of resistance to benzimidazol and dicarboximide fungicides in Botryotinia fuckeliana (Botrytis cinerea). Mycol Res. 95:943-951.

8. Faretra, F., and Pollastro, S. 1996. Genetic studies of the phytopathogenic fungus Botryotinia fuckeliana (Botrytis cinerea) by analysis of ordered tetrads. Mycol Res. 100:620624 .

9. Fraile, A., Alonso, Al, and Sagasta, E. M. 1986. Some characteristics of Botrytis cinerea isolates tolerant to procymidone. Plant Pathol. 35:82-85.
10. Garber, M. P., Hudson, W. G., Norcini, J. G., Thomas, W. A., Jones, R. K., and Bondari, K. 1997. Biologic and Economic Assessment of Pest Management in the United States Greenhouse and Nursery Industry. Coop. Ext. Serv. Univ. GA, Athens.

11. Georgopoulos, S. G., and Skylakakis, G. 1986. Genetic variability in the fungi and the problem of fungicide resistance. Crop. Prot. 5:299-305.

12. Hisada, Y., Kata, T., and Noda, C. 1984. Biological properties of procymidone-resistant field isolates of Botrytis cinerea. Ann. Phytopathol. Soc. Jpn. 50:590-599.

13. Hunter, T., Brent, K. J., Carter, G. A., and Hutcheon, J. A. 1987. Effects of fungicide spray regimes on incidence of dicarboximide resistance in gray mould (Botrytis cinerea) on strawberry plants. Ann. Appl. Biol. 110:515525.

14. Jarvis, W. R. 1992. Managing Diseases in Greenhouse Crops. APS Press, St. Paul, MN.

15. Johnson, K. B., Sawyer, T. L., and Powelson, M. L. 1994. Frequency of benzimidazole- and dicarboximide-resistant strains of Botrytis cinerea in western Oregon small fruit and snap bean plantings. Plant Dis. 78:572-577.

16. Katan, T. 1982. Resistance to 3,5-dichlorophenyl-N-cyclic imide ('dicarboximide') fungicides in the gray mould pathogen $\mathrm{Bo}$ trytis cinerea on protected crops. Plant Pathol. 31:133-141.

17. LaMondia, J. A., and Douglas, S. M. 1997. Sensitivity of Botrytis cinerea from Connecticut greenhouses to benzimidazole and dicarboximide fungicides. Plant Dis. 81:729732.

18. Leroux, P., and Clerjeau, M. 1985. Resistance of Botrytis cinerea Pers. and Plasmopara viticola (Berk. \& Curt.) Berl and de Toni to fungicides in French vineyards. Crop. Prot. 4:137-160.

19. Löcher, F. J., Lorenz, G., and Beetz, K.-J. 1987. Resistance management strategies for dicarboximide fungicides in grapes: Results of six years' trial work. Crop. Prot. 6:139-147.

20. Locke, T., and Fletcher, J. T. 1988. Incidence of benomyl and iprodione resistance in isolates of Botrytis cinerea in tomato crops in England and Wales in 1986. Plant Pathol. 37:381-384.

21. Moorman, G. W., and Lease, R. J. 1992. Benzimidazole- and dicarboximide-resistant Botrytis cinerea from Pennsylvania greenhouses. Plant Dis. 76:477-480.

22. Moorman, G. W., Lease, R. J., and Vali, R. J. 1994. Bioassay for dicarboximide resistance in Botrytis cinerea. Plant Dis. 78:890-891.

23. Northover, J. 1988. Persistence of dicarboximide-resistant Botrytis cinerea in Ontario vineyards. Can. J. Plant. Pathol. 10:123-132.

24. Northover, J., and Matteoni, J. A. 1986. Resistance of Botrytis cinerea to benomyl and iprodione in vineyards and greenhouses after exposure to the fungicides alone or mixed with captan. Plant Dis. 70:398-402.
25. Pak, H. A., Beever, R. E., and Laracy, E. P. 1990. Population dynamics of dicarboximideresistant strains of Botrytis cinerea on grapevine in New Zealand. Plant Pathol. 39:501-509.

26. Panayotakou, M., and Malathrakis, N. E. 1983. Resistance of Botrytis cinerea to dicarboximide fungicides in protected crops Ann. Appl. Biol. 102:293-299.

27. Pommer, E.-H., and Lorenz, G. 1982. Resistance of Botrytis cinerea Pers. to dicarboximide fungicides-a literature review. Crop. Prot. 1:221-230.

28. Snedecor, G. W., and Cochran, W. G. 1989 Statistical Methods, 8th Edition. Iowa State University Press, Ames.

29. Stehmann, C., and De Waard, M. A. 1996. Sensitivity of populations of Botrytis cinerea to triazoles, benomyl, and vinclozolin. Eur. J. Plant Pathol. 102:171-180.

30. Tanaka, K., Kiso, A., and Araki, T. 1987. A simple method for screening chemicals using cucumber cotyledons and paper disks to Botrytis cinerea. Ann. Phytopathol. Soc. Jpn. 53:65-66.

31. Vali, R. J., and Moorman, G. W. 1992. Influence of selected fungicide regimes on frequency of dicarboximide-resistant and dicarboximide-sensitive strains of Botrytis cinerea. Plant Dis. 76:919-924

32. Wang, Z., and Coley-Smith, J. R. 1986 Studies on some characteristics of dicarboximide-resistant isolates of Botrytis cinerea from protected lettuce. Plant Pathol. 35:544 550.

33. Wang, Z., Coley-Smith, J. R., and Wareing, P. W. 1986. Dicarboximide resistance in Botryti cinerea in protected lettuce. Plant Pathol. 35:427-433.

34. Washington, W. S., Shanmuganathan, N., and Forbes, C. 1992. Fungicide control of strawberry fruit rots, and the field occurrence of resistance to Botrytis cinerea to iprodione, benomyl, and dichlofluanid. Crop. Prot. 11:355-360.

35. Yarden, O., and Katan, T. 1993. Mutations leading to substitutions at amino acids 198 and 200 of beta-tubulin that correlate with benomyl-resistance phenotypes of field strains of Botrytis cinerea. Phytopathology 83:1478-1483.

36. Yourman, L. F., and Jeffers, S. N. 1996 Sensitivity of isolates of Botrytis cinerea from South Carolina greenhouses to benzimidazole and dicarboximide fungicides. (Abstr.) XI Int. Botrytis Symp. Wageningen, The Netherlands.

37. Yourman, L. F., and Jeffers, S. N. 1997. Resistance to benzimidazole and dicarboximide fungicides in isolates of Botrytis cinerea from South Caroline greenhouses. (Abstr.) Phytopathology 87:S116.

38. Yunis, H., and Elad, Y. 1989. Survival of dicarboximide-resistant strains of Botrytis cinerea in plant debris during summer in Israel. Phytoparasitica 17:13-21. 